\title{
IMPLANTAÇÃO DE UMA ÁREA DE ASSISTÊNCIA PARA O ENSINO DE ENFERMAGEM PSIQUIÁTRICA NA UNIVERSIDADE FEDERAL FLUMINENSE
}

\author{
Maria Wanda Rodrigues de Oliveira * \\ Maria Emília Almeida Porto *
}

Desde 1944, data da fundação da Escola, na época Escola de Enfermagem do Estado do Rio de Janeiro, até 1956, o ensino de Enfermagem Psiquiátrica se desenvolvia teoricamente, baseado em programação de conteúdo clínico, com experiências de enfermagem bastante limitadas no campo prático em virtude da falta de enfermeira orientada especificamente para este setor.

Atendida essa premissa básica com a contratação de um docente, o campo clínico passou a ser a próxima etapa de trabalho. E, após estudo exploratório dos recursos oferecidos pela Comunidade Fluminense nesta área, foi escolhido o Hospital Psiquiátrico de Jurujuba, por encontrar-se nas mesmas condições técnico-administrativas das demais instituiçōes psiquiátricas do Estado e localizar-se na época, próximo à sede da Escola.

Nessa ocasião, a quase totalidade dos hospitais psiquiátricos não preenchiam os requisitos desejáveis para um campo de aprendizagem destinado à estudantes de enfermagem. No entanto, algumas escolas do País, davam seus primeiros passos com este objetivo. A Escola Ana Néri, já havia iniciado suas atividades no Instituto Psiquiátrico da antiga Universidade do Brasil. Tornara-se evidente, a necessidade de enfrentar o desafio que eram os hospitais psiquiátricos tradicionais, para que se pudesse dar início a uma nova jornada no setor assistencial psiquiátrico no Estado do Rio de Janeiro e garantir ao estudante fluminense, experiências em uma especialiclade que ganhava dimensão a cada dia no cenário das ciências médicos, orientando-se para o estudo multifatorial da pessoa humana como um todo integrado.

* Professores da Escola de Enfermagem da Universidade Federal Fluminense. 
Convém salientar que, em 1960, no Perú, sob o patrocínio da O.M.S., um grupo de líderes de enfermagem de vários países latinoamericanos, ao apreciar as relaçōes das Escolas de Enfermagem com outras instituições onde seus estudantes vão cumprir um programa de ensino teórico-prático, recomendava a colaboração das Escolas na elevação do nível técnico das referidas instituições assistenciais. garantindo-se ao mesmo tempo, liberdade de ação no que se refere ao ensino, situação esta que deveria ser concretizada por acordo das partes interessadas. Essa referência nos pareceu importante uma vez que era exatamente o que procurávamos assegurar na época: HEspital Psiquiátrico de Jurujuba abria suas portas à primeira instituição de ensino que o procurava e nossa colaboração no plano assistencial tornava-se uma necessidade imperiosa em virtude dos problemas com os quais o Hospital se deparava.

\section{O HOSPITAL PSIQUIÁTRICO DE JURUJUBA}

Ninguém ignora que o clamor pela reestruturação dos hospitais psiquiátricos continua sendo, ainda hoje, a tônica da política assistencial. Este fato se evidencia claramente na literatura e nos temas debatidos nos Congressos da especialidade. Em 1965, no artigo "A enfermagem psiquiátrica na realidade brasileira" de autoria da Professora Teresa Sena, destacamos: "Em quase nada estamos cliferentes, considerando os hospitais do II Império e a relação que guardam o nossos atuais hospitais colônias: Juquirí, Barbacena, Juliano Moreira, Tamarineira, Hospital Colônia Psicopata (Ceará), San Meduna (Piauí), Hospital Colônia Nena Rodrigues (Maranhão), Hospital Colônia Eduardo Ribeiro (Amazonas), etc..."

Em 1970, Clovis Martins, em tema apresentado no VI Congresso Iatino Americano de Psiquitrria, afirmava: "Hospitais Psiquiátricos ultrapassados, sombrios, desconfortáveis, mal aparelhados, arrastando-se penosamente na história de nossa medicina, num anacronismo de no mínimo 50 anos".

O Hospital Psiquiátrico de Jurujuba não podia fugir a estas circunstâncias. Construído em 1944 para 250 leitos, em linhas modernas, e com instalaçōes razoáveis para serviços complementares, encontrava-se em 1956, abrigando 400 pacientes em média, que disputavam uma cama para dormir e um lugar no refeitório para se alimentar. A super-lotação aliada à falta de pessoal convenientemente preparado haviam transformado toda aquela estrutura, tornando-a inóspita e anti-humana.

Em linhas gerais, este era o quadro que se nos apresentava e que teria de ser tratado de alguma forma, uma vez que não poGeríamos pretender encontrar um campo clínico adequado ao ensino da enfermagem psiquiátrica. Pareceu-nos mais real e coadu- 
nando com uma política mais construtiva em prol de melhores níveis de assistência, utilizar esse campo, mesmo que as perspectivas para a sua adequação fossem bastante remotas.

\section{TENTATIVAS PARA ADEQUAÇÃO DO CAMPO CLINICO}

Vários aspectos teríamos que considerar nesta trajetória. Em primeiro lugar, definir as possibilidades de aprendizagem que seria cferecida ao estudante nas circunstâncias referidas. Cremos que se os discentes não pudessem ter uma programação que os habilitassem adequadamente à especialidade, pelo menos alguns objetivos poderiam ser atendidos, entre os quais assinalaríamos como de grande importância, a conscientização da problemática assistencial psiquiátrica e a responsabilidade da enfermagem nas reformas que se preconizam para as instituições psiquiátricas. Levando em consideração $\cap$ atendimento do estudante, diríamos que todo o processo de ensino que se afasta de uma realidade não está preparando o profissional capaz de assumir o seu papel dentro da comunidade.

Em levantamento estudado por nós sobre a situação da enfermagem psiquiátrica no Estado do Rio de Janeiro, encontramos, nas 13 instituições psiquiátricas que responderam ao nosso questionário 4059 leitos, assistidos por 18 enfermeiros, 163 auxiliares de enfermagem (alguns apenas nomeados como auxiliares), 107 atendentes e 1139 serviçais que foram computados por prestarem cuidados de enfermagem aos pacientes (1).

Estes números demonstram claramente a necessidade de motivar pessoal profissional para esta área.

Em seu lugar, colaborar com a Instituição, sem assumir a responsabilidade total do serviço de enfermagem. Neste sentido, procuramos conhecer o Hospital como um todo e após algumas semanas de observação, encaminhamos um relatório ao seu Diretor, sugerindo um esquema de trabalho que viria facilitar o equacionamento de medidas básicas, elegendo um setor que abrigava 210 leitos (enfermaria feminina), para aplicação prática das nossas atividades de ensino. A seleção de atividades na fase de organização da área, ¿̀e maneira que permitisse a participação dos estudantes em todas as etapas de trabalho previstas, foi um dos aspectos considerados como prioritários na programação do curso.

A atuação das alunas, nesta fase, teve um significado especial no ambiente hospitalar, influenciando positivamente a atitude dos atendentes em relação aos pacientes. Lamentavelmente, por mudança de direção do hospital e pelo envolvimento nas tarefas administrativas de uma área muito ampla, sentimo-nos sem conGições de dar ao que nos havíamos proposto, ou seja, colaborar com 
a administração e assegurar em tempo mínimo, campo clínico adequado aos estudantes; no entanto, a atividade integrada no corpo do hospital, facilitou-nos a delimitação do campo num setor menor, uma enfermaria com 30 leitos, sob a responsabilidade do Professor de clínica Psiquiátrica da Escola, com o qual estabelecemos algumas normas de funcionamento que ficaram garantidas no contexto funcional do Hospital.

Essa experiência foi muito interessante do ponto de vista do estudante, porém, deparamos com outra dificuldade: estando a enfermaria localizada no meio de outras cujo atendimento era bastante deficiente, criava-se uma situação muito injusta para os demais pacientes da área, uma vez que se formava um grupo privilegiado dentro da comunidade hospitalar.

Essas tentativas foram válidas dentro do ambiente hospitalar, porque procurávamos dar um testemunho da atuação da enfermagem apesar das condições deficitárias do hospital. Foi então, que recebemos da Direção, uma área independente, constituída de 1 enfermaria, 2 quartos individuais, postos de enfermagem, refeitório, rouparia, copa e local ao ar livre para atividades ocupacionais e recreacionais. Para essa área se decidiu que seriam encaminhados os pacientes admitidos nas enfermarias gerais, selecionados entre aqueles que necessitassem tratamento intensivo, permitindo uma mobilização nos leitos com um índice de altas apreciável.

O afastamento do pessoal docente e discente por motivo de férias regulamentares ou outros impedimentos, não nos permitiu a manutenção desse trabalho, uma vez que o déficit de pessoal existente no hospital não oferecia condições para a continuidade do mesmo nesses períodos. Sempre porém ficava uma boa imagem do estudante de enfermagem e creio que foi essa imagem, que através de todos esses anos, contribuiu para a afirmação da posição da Escola na entidade.

Em 1965, um novo fato veio fortalecer a nossa posição: A Faculdade de Medicina após reforma curricular, teve que incluir o ensino prático de Clínica Psiquiátrica e não dispunha de campo apropriado e como já existia esse trabalho iniciado pela Escola de Enfermagem, após várias reuniōes, ficou decidida a organização de uma área de 4 enfermarias com 100 leitos, cuja assistência ficaria em grande parte com a UFF. Com base nessa resolução, foi contratado pessoal técnico para enfermagem, ficando os mesmos subordinados a Escola, coordenados pelo professor responsável pela disciplina Enfermagem Psiquiátrica.

Atualmente, o Hospital Psiquiátrico mantém um serviço de enfermagem chefiado por um enfermeiro (ex-aluno da Escola), possibilitando melhor relacionamento entre as funçōes de ensino e assistência. 
Uma equipe multiprofissional começa a se esboçar e com a reestruturação do Serviço de Nutrição, estudantes desse curso passaram a se interessar pela área e da mesma forma, estudantes. de Serviço Social, após a contratação de uma assistente social.

Colocamos em prática, uma programação com a finalidade de equacionar medidas que possam ampliar o campo clínico para as experiências estudantís. Assim foi que elaboramos as rotinas para as clínicas, objetivando o equilíbrio funcional do pessoal de enfermagem, entrosamos o nosso pessoal com o Serviço de Nutrição a fim de que o doente fosse mais bem atendido em sua alimentação; iniciamos uma programação de atendimento da família dos pacientes por ocasião da visita dos mesmos, integrando enfermeiros e assistentes sociais; entramos em contato com o auxiliar de terapia ocupacional, que por não dispor de recursos relativos a pessoal e rnaterial, mantém a área praticamente inativa, propondo o aproveitamento de algumas horas do pessoal auxiliar de enfermagem neste setor, visando diminuir o tempo ocioso dos nossos pacientes através de uma programação de atividades ocupacionais e recreacionais.

Muitas outras medidas, além da efetivação das acima referidas, nos preocupamos nesta linha que defendemos: melhorar as conciições do campo clínico, acreditando que sempre poderemos fazer um pouco mais, muito embora enfrentando sérios obstáculos.

Algo começa a ser percebido: o hspital que ainda vive regime asilar, não tem o aspecto de 16 anos atrás e o pessoal que constitui a equipe de assistência já demonstra uma atitude mais positiva em relação às necessidades do paciente.

\section{O ENSINO DE ENFERMAGEM PSIQUIÁTRICA NA EEUFF}

$\mathrm{Na}$ descrição anterior, procuramos definir nossa posição em relação ao ensino de Enfermagem Psiquiátrica. Cabe-nos ainda considerar alguns pontos de real importância na situação presente: as estatísticas da Divisão Nacional de Saúde Mental no quinquênio 65/70, comprovam que dos 4937 guardas e vigilantes, passamos para 10408 e que do pessoal de enfermagem que qualificam de não diplomados, de 1025 para 2746 atuando na assistência psiquiátrica.

Os hospitais psiquiátricos, nesse mesmo período, passaram de 69503 admissões para 137305 e as readmissões de 38497 para 76712 . Fortanto, a assistência psiquiátrica prossegue como um sério desafio na. área de Saúde, o "leito chão" $\left(^{*}\right)$ permanece, a regressão de comportamento continua sendo cultivada e há acúmulo de pacientes sem destino na cômoda categoria de pacientes crônicos.

(*) Leito chão - diferença entre o número de cama e o número de doente. 
Salientados estes pontos, não vemos outra alternativa, senão aquela já definida: o estudante necessita participar dessa evidência e adequar sua atuação e técnicas, desde que não sejam atingidcs Cs princípios éticos que devem estar presentes no processo de enfermagem; se não enfrentarmos estas estruturas, com todas as deficiências existentes, o contingente de guardas e vigias continuarão a crescer e florescer no campo da assistência psiquiátrica e o que mais esperar, se o número de ingressos continua a desafiar o número de leitos disponíveis?

Ensinar é um processo de alta complexidade e quando está em jogo a problemática do homem doente, o plano de assistência terá que inter-relacionar corpo, mente e emoções a fim de que o ensino seja dirigido ao homem e não è enfermidade, resultando disto, dois aspectos a serem consiaierados em relação ao estudante: o planejamento do cuidado de enfermagem dentro de uma avaliação globa] das necsssidades do paciente e um ambiente físico e social adequado.

Tratando-se de enfermagem psiquiátrica, não podemos deixar de conceituar o paciente e o cuidado de enfermagem nas contingências em que se atua: o doente mental é um paciente que continua pagando um alto preço à sociedade porque sua mente se desarmonizou, pesando sobre sí velhos tabus, que até certo ponto poderão ser interpretados como responsáveis pela não observância de uma assistência adequada. Baseado nos conceitos emitidos pelos trabalhos de Marcelo Blaya das clínicas Pinel do Rio Grande do Sul, podemos dizer que o doente mental é uma pessoa dissociada em partes doentes" e "partes sadias" e que no plano assistencial de enfermagem as "partes sadias" devem ser consideradas no sentido rẹe não transformá-lo no "doente incapaz".

Ensinar enfermagem psiquiátrica onde a família continua a reieitar seus pacientes, onde a situação econômica é responsável pelo alargamento do tempo de permanência do internado, onde a comunidade desconhece o seu papel na readaptação e recuperação do dcente mental, implica em não apenas adestrar o estudante para clínicas psiquiátricas, e sim, prepará-los dentro de uma dimensão mais ampla, de maneira que em qualquer setor que venha a desenvclver suas atividades profissionais, possa colaborar no sentido da educação da própria comunidade.

Foi acreditando nesses pressupostos que, durante todos esses anos, elegemos como objetivos fundamentais na programação da aisciplina: a) ajudar o estudante a adquirir uma atitude correta frente ao doente mental; b) ajudar o estudante a enfrentar as instituiçōes trađicionais e precárias, configurando nesse trabalho, a possibilidade do enfermeiro com sua influência, operar mudanças nesses ambientes; c) auxiliar o estudante a compreender a problemática assistencial psiquiátrica é também uma problemática de saú- 
de como a de doenças infecto-parasitárias, materno-infantil etc.; e, sendo o enfermeiro um educador, lhe compete também nesta área, 1 ) esclarecimento da comunidade.

Concluindo, diremos que ainda não chegamos à fase de uma enfermagem terapêutica, porém, continuamos lutando para alcançáJa, mas, se estivéssemos esperando um campo adequado, cremos que ainda estaríamos visitando os pacientes, encaminhando os relatórios negativos dessas situações, sem nada tentar para a transformação que se fazia necessária; daí porque, docentes e discentes de mãos dadas, construíram esta resenha histórica, que acreditamos ter apenas o mérito de servir de estímulo para outros colegas que, em lugares distantes, queiram dar os primeiros passos dentro dos grandes asilos que perduram em nosso País.

\section{BIBLIOGRAFIA}

1. OLIVEIRA, Maria Wanda Rodrigues - Levantamento da assistência de Enfermagem Psiquiátrica no Estado do Rio de Janeiro. VI Congresso Latino-Americano de Psiquatria. São Paulo. 1970.

2. LAPIS, B. R., RODRIGUES, J. e MYLUS, Rute - Enfermagem Psiquiátrica - sua função. Revista Brasileira de Enfermagem, 1 e 2: 64-69, jan-mar, 1971.

3. FERNANDES, D. A. B. - Assistência Psiquiátrica através da Divisão de Saúde Mental e o ensino prático de enfermagem Psiquiátrica. Revista Brasileira de Enfermagem, 6:547-555 dez, 1968.

4. BAPTISTA, Wanda Alves - Relação Escola - Campo de Estágio. Revista Brasileira de Enfermagem, 4: 318-322, agosto, 1966.

5. SENA, Teresa - A enfermagem Psiquiátrica na realidade brasileira. Revista Brasileira de Enfermagem, 18: 350-7, out, 1965.

6. MARTINS, Clovis - Reflexões sobre a assistência psiquiátrica na América Latina. Relatório oficial - VI Congresso Latino-Americano de Psiquiatria e I Congresso Brasileiro de Psiquiatria. São Paulo. 1970.

7. O.M.S. - Guia para Escuelas de Enfermeria. Organização Panamericana de Saúde. 1960. 